\title{
Cellular Sites for Activation of $\delta$-Opioid Receptors in the Rat Nucleus Accumbens Shell: Relationship with Met $^{5}$-Enkephalin
}

\author{
Adena L. Svingos, Cathy L. Clarke, and Virginia M. Pickel \\ Department of Neurology and Neuroscience, Division of Neurobiology, Cornell University Medical College, New York, \\ New York, 10021
}

\begin{abstract}
The shell compartment of the nucleus accumbens (AcbSh) is prominently involved in the rewarding aspects of $\delta$-opioid receptor (DOR) agonists, including one of its putative endogenous ligands, Met ${ }^{5}$-enkephalin (Enk). We examined the ultrastructural immunocytochemical localization of an antipeptide DOR antiserum and an antibody against Enk to determine the major cellular sites for DOR activation and the spatial relationship between DOR and Enk in this region. Sixty percent of DOR-immunoreactive profiles were axon terminals and small unmyelinated axons, whereas the remainder were mainly dendrites and dendritic spines. In axons and terminals, DOR labeling was distributed along plasma and vesicular membranes. DOR-containing terminals were mainly large and primarily formed symmetric synapses or occasionally asymmetric synapses. DOR immunoreactivity also was associated with terminals that were small and formed punctate symmetric or nonrecognizable synapses. Dual immunoperoxidase and immunogold
\end{abstract}

labeling showed that $35 \%$ of DOR-labeled axons apposed other terminals that contained Enk. In addition, 25\% of the DOR-labeled terminals contained Enk. Thirty-five percent of DOR labeling was observed within dendrites and dendritic spines. DOR-labeled spines showed intense immunoreactivity within asymmetric postsynaptic junctions, which were formed by terminals that lacked Enk immunoreactivity. DOR-labeled spines, however, were apposed to Enk-containing terminals in $13 \%$ of all associations between dually labeled profiles. These results provide ultrastructural evidence that activation of DOR in the AcbSh is primarily involved in modulating the presynaptic release of mainly inhibitory, but also excitatory, neurotransmitters. These data also suggest that DOR plays a role in determining the postsynaptic response to excitatory afferents.

Key words: enkephalin; reinforcement; ultrastructure; electron microscopy; nucleus accumbens; opiate
The nucleus accumbens (Acb) is a primary brain region involved in the locomotor and rewarding behaviors associated with administration of $\delta$-opioid receptor (DOR) ligands (Shippenberg et al., 1987; Churchill and Kalivas, 1992; Negus et al., 1993). Infusion of DOR-specific agonists into the Acb, for example, results in enhanced locomotor activity, including stereotypy, and also produce reinforcing behaviors such as conditioned place preference (Goeders et al., 1984; Dauge et al., 1988; West and Wise, 1988; Longoni et al., 1991; Suzuki et al., 1994; Meyer et al., 1995). Furthermore, selective lesioning of the Acb abolishes the reinforcing effects of DOR agonists (Shippenberg and Herz, 1988), including heroin (Zito et al., 1985). These behaviors appear to reflect primarily the limbic shell region of the Acb, suggesting that this area also is a site for DOR-mediated reinforcing behaviors (Mogenson et al., 1980; Alheid and Heimer, 1988).

The behavioral effects induced by DOR agonist administration are thought to occur through DOR-mediated modulation of transmitter release (for review, see Mulder and Schoffelmeer, 1993). In this regard, GABAergic and glutamatergic transmission in the Acb and other brain areas is attenuated by DOR agonist administration (Yuan et al., 1992; Glaum et al., 1994; Tanaka and North, 1994). In addition, DOR agonists are known to increase dopamine efflux and turnover in the Acb (Spanagel et al., 1990; Pentney and Gratton, 1991; Suzuki et al., 1997). Furthermore,

\footnotetext{
Received Sept. 10, 1997; revised Oct. 21, 1997; accepted Oct. 23, 1997.

This work was supported by an Aaron Diamond Foundation Postdoctoral Fellowship to A.L.S. and National Institute on Drug Abuse Grant DA04600 to V.M.P.

Correspondence should be addressed to Dr. Adena L. Svingos, Department of Neurology and Neuroscience, Division of Neurobiology, Cornell University Medical College, 411 East 69th Street, New York, NY, 10021.

Copyright (C) 1998 Society for Neuroscience $0270-6474 / 98 / 181923-11 \$ 05.00 / 0$
}

DOR stimulation results in decreased release of acetylcholine in this region (Lapchak et al., 1989; Heijna et al., 1990, 1992; Sandor et al., 1992). DOR activation may modulate presynaptic transmitter release or the postsynaptic affects of transmitter function through changes in ion channel flux (North et al., 1987; Stefani et al., 1994).

Autoradiographic studies of selective DOR ligands reveal a diff use binding profile for the receptor in the ventral region of the striatum, including the shell compartment of the nucleus accumbens (AcbSh) (Mansour et al., 1987; Gouarderes et al., 1993). In addition, in situ hybridization studies show that neurons within both the shell and core regions of the Acb express DOR mRNA (Mansour et al., 1995). The neuronal distribution of DOR within the AcbSh, however, has not been established firmly, nor has the cellular relationship between DOR and its putative endogenous ligand $\mathrm{Met}^{5}$-enkephalin (Enk) been investigated in this region. In the present study, we used an antipeptide antiserum against DOR and an antibody against Enk combined with high-resolution electron microscopy to examine (1) the cellular distribution of the receptor within the rat AcbSh and (2) the spatial relationship between DOR and Enk in this region. Our results provide the first ultrastructural evidence for the prominent involvement of DOR in the presynaptic release of transmitter from morphologically and perhaps chemically heterogenous axon terminals, including those that contain Enk. We also show that DOR immunoreactivity is present along selective asymmetric synaptic and nonsynaptic sites in dendritic spines, suggesting that DOR activation could mediate postsynaptic responses to opiates or other, mainly excitatory, neurotransmitters within spiny neurons in the AcbSh. 


\section{MATERIALS AND METHODS}

Antibody specificity. The p34 peptide, corresponding to amino acids 34-47 of an extracellular fragment of the N-terminal domain of the cloned DOR receptor, was synthesized, and a polyclonal antibody was generated in guinea pigs (Immuno-Dynamics, La Jolla, CA). The chosen peptide had an amino acid sequence known not to occur in other nonopioid receptors, or other proteins, as shown by searches in GenBank. The p34 antibody was subsequently characterized by (1) immunodot blots, (2) immunocytochemical labeling of NG-108 cells and cervical spinal cord tissue sections, and (3) preadsorption of labeled cells and tissue with the parent peptide (Cheng et al., 1995). The results from Cheng et al. (1995) showed that the p34 DOR antibody did not crossreact with other $\mu$ - or $\kappa$-opioid receptors. In addition, the p34 antibody labeled NG-108 cells and the dorsal horn of the spinal cord. DOR labeling was significantly decreased in NG-108 cells and rat spinal cord when coincubated with the parent peptide.

A rabbit polyclonal antiserum raised against Met $^{5}$-enkephalin was obtained commercially from Incstar (Stillwater, MN). Immunodot blots revealed that the $\mathrm{Met}^{5}$-enkephalin antibody reacts principally with $\mathrm{Met}^{5}$ enkephalin and has a more limited recognition of $\mathrm{Leu}^{5}$-enkephalin and no cross-reaction with endorphin or dynorphin A (Cheng et al., 1995).

Immunocytochemistry. Adult male Sprague Dawley rats were anesthetized with $100 \mathrm{mg} / \mathrm{kg}$ sodium pentobarbital intraperitoneally and perfused through the ascending aorta with (1) $10 \mathrm{ml}$ of heparin $(1000 \mathrm{U} / \mathrm{ml})$ in saline, (2) $50 \mathrm{ml}$ of $3.75 \%$ acrolein (Polysciences, Warrington, PA) in a solution of $2 \%$ paraformaldehyde and $0.1 \mathrm{~m}$ phosphate buffer (PB), $\mathrm{pH}$ 7.4 , and (3) $200 \mathrm{ml}$ of $2 \%$ paraformaldehyde. The brains were then removed and post-fixed for $30 \mathrm{~min}$ in $2 \%$ paraformaldehyde. After sectioning at $30-40 \mu \mathrm{m}$ on a vibratome, the tissue was treated with $1 \%$ sodium borohydride in $0.1 \mathrm{M}$ PB to remove excess aldehydes. Tissue sections were then freeze-thawed to enhance penetration of immunoreagents. For this, tissue was incubated in a cryoprotectant solution containing $25 \%$ sucrose and $2.5 \%$ glycerol in $0.05 \mathrm{M} \mathrm{PB}$ and then immersed successively in (1) liquid freon, (2) liquid nitrogen, and (3) room temperature PB. Tissue sections were then rinsed in $0.1 \mathrm{M} \mathrm{PB}$, followed by 0.1 M Tris-buffered saline (TBS), $\mathrm{pH}$ 7.6. Sections were incubated for $30 \mathrm{~min}$ in $1 \%$ bovine serum albumin in TBS to minimize nonspecific labeling and then processed for immunocytochemistry.

For single-labeling experiments with DOR, pretreated tissue sections were incubated for $48 \mathrm{hr}$ at $4^{\circ} \mathrm{C}$ in primary guinea pig antiserum p34 (1:2000). For dual-labeling experiments, tissue sections were incubated in a solution containing the p34 antiserum (1:2000) and the antibody against Enk $(1: 20,000)$. For immunoperoxidase detection of DOR, sections were incubated in (1) 1:400 biotinylated goat anti-guinea pig $\operatorname{IgG}$ (Amersham, Arlington Heights, IL) and (2) 1:200 peroxidase-avidin complex (Hsu et al., 1981). The peroxidase reaction product was visualized with $22 \mathrm{mg}$ of 3,3'-diaminobenzidine (Aldrich, Milwaukee, WI) in $10 \mu \mathrm{l}$ of $30 \% \mathrm{H}_{2} \mathrm{O}_{2}$ and $100 \mathrm{ml}$ of TBS for $6 \mathrm{~min}$. All incubations were performed at room temperature (unless otherwise noted) with continuous agitation. Sections were rinsed with TBS between incubations.

The method of Chan et al. (1990) was used for pre-embedding peroxidase-immunogold dual labeling of the tissue. For immunogold-silver detection of Enk, tissue sections that were processed for DOR were then (1) incubated for $2 \mathrm{hr}$ in colloidal gold $(1 \mathrm{~nm})$-labeled anti-rabbit IgG (1:50), (2) fixed for $10 \mathrm{~min}$ in $2 \%$ glutaraldehyde in PBS, and (3) reacted for 5-10 min with a silver solution (IntenSE kit, Amersham).

For electron microscopic detection of the Enk and/or DOR antisera, tissue sections were post-fixed with $2 \%$ osmium tetroxide in $0.1 \mathrm{M} \mathrm{PB}$ for $1 \mathrm{hr}$, dehydrated through graded ethanols and propylene oxide, and embedded in Epon 812 between two sheets of Aclar plastic (Leranth and Pickel, 1989). Ultrathin tissue sections $(40-50 \mathrm{~nm})$ were cut through the AcbSh at the levels of plates 11-13 of the rat brain atlas of Paxinos and Watson (1986). Thin sections were cut with a diamond knife (Diatome) and collected on copper mesh grids in serial order from the outer surface of the tissue. The sections were then counterstained with uranyl acetate and lead citrate (Reynolds, 1963) and examined with a Phillips 201 electron microscope.

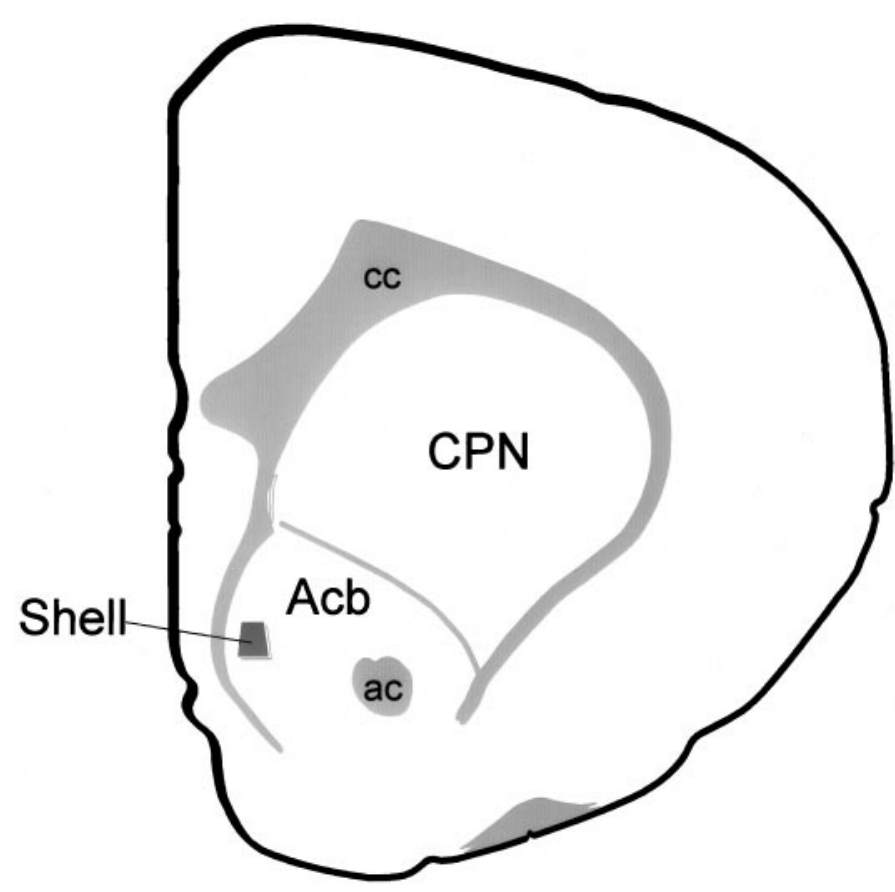

Figure 1. Coronal hemisection of the rat forebrain. Schematic diagram illustrating the region of the Acb shell that was sampled for electron microscopic analysis. $a c$, Anterior commissure; $A c b$, nucleus accumbens; $c c$, corpus callosum; $C P N$, caudate-putamen nucleus. Modified from Swanson (1992).

Assessment of cellular elements. The classification of labeled cellular elements was based on descriptions by Peters et al. (1991). Soma were identified by the presence of nuclei. Dendrites were identified by the presence of postsynaptic densities and/or an abundance of endoplasmic reticulum and microtubules. Small unmyelinated axons were $<0.1 \mu \mathrm{m}$ in diameter and rarely contained small vesicles. Small axon terminals were between 0.1 and $0.5 \mu \mathrm{m}$ in diameter and occasionally contained small synaptic vesicles. Large axon terminals contained a relative abundance of small synaptic vesicles and were between 0.5 and $1.5 \mu \mathrm{m}$ in diameter. Synapses were characterized as either asymmetric (thick postsynaptic densities) or symmetric (thin postsynaptic densities). Nonsynaptic contacts or appositions were defined as close membranous associations that lacked recognizable specializations but were not otherwise separated by astrocytic processes. "Perisynaptic" was defined as the area of the dendritic plasma membrane that was adjacent to the postsynaptic density. "Extrasynaptic" was defined as that area of the dendritic plasma membrane that was not adjacent to the synaptic junction. "Nonsynaptic" was defined as that area of dendritic plasma membrane that did not include the synaptic specialization.

Data analysis. The total field used for analysis of labeled profiles was taken from electron micrographs that were chosen based on the presence of labeling for the antigen(s) of interest and morphological integrity. The presence of labeled profiles was verified by examining serial tissue sections when possible. Assessment of the number of DORimmunoreactive profiles in singly labeled tissue was based on three to five vibratome sections taken from four animals. The percentage of labeled profile type (i.e., dendrites vs terminals) was based on all DORlabeled elements $(n=626)$. The incidence of contacts between and colocalizations of DOR- and Enk-labeled profiles was based on the total number of DOR-labeled profiles taken from dually labeled tissue sections $(n=454$ DOR-labeled profiles, taken from three to five vibratome

including a mitochondrion $(m)$ and smooth endoplasmic reticulum (SER). This terminal forms an asymmetric synapse (curved arrow) with a spine (US) that appears unlabeled when compared with the dendritic postsynaptic density in $D$. D, A DOR-labeled small terminal (DOR-st) is apposed to a DOR-immunoreactive dendrite. The dendritic DOR immunoreactivity is localized to a synapse (curved arrow) that is formed by an unlabeled terminal $(U T)$. A small unmyelinated axon $(D O R-a)$ reveals delicate DOR labeling around the plasma membrane. Scale bars, $0.22 \mu \mathrm{m}$. 

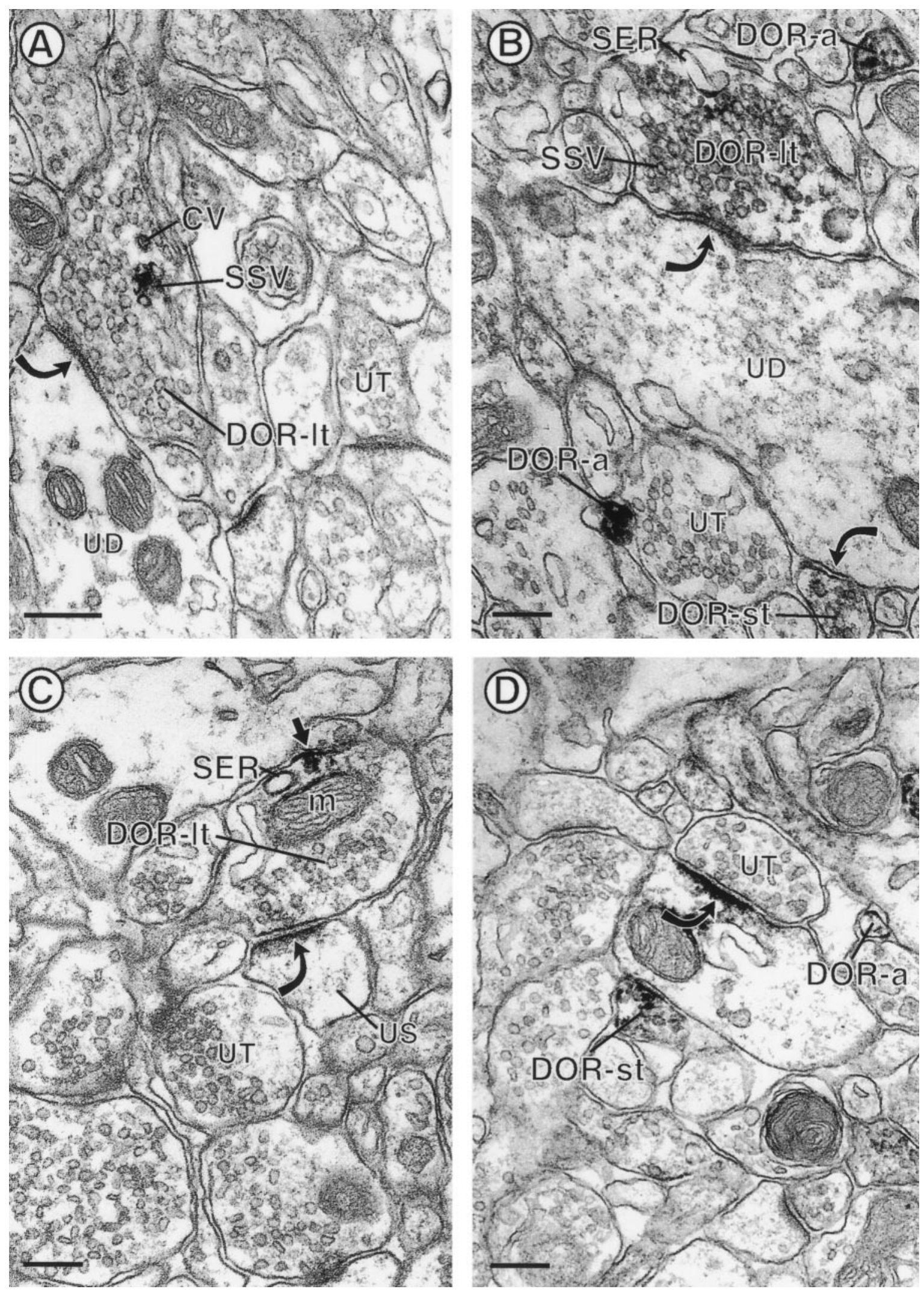

Figure 2. Electron micrographs showing immunoperoxidase DOR-LI in large axons, small axon terminals, and small unmyelinated axons. The axon large terminals in $A$ and $B(D O R-l t)$ contain small synaptic vesicles $(S S V)$ that are rimmed with a dense black precipitate indicative of DOR-LI. The DOR-labeled terminal in $A$ also contains a coated vesicle $(C V)$ that is immunoreactive for DOR. Both DOR-labeled terminals form symmetric-type synapses (curved arrows) with unlabeled dendrites $(U D)$. B, A DOR-immunoreactive small axon terminal (DOR-st) forms a symmetric synapse (curved arrow) with $U D$ and two small DOR-immunoreactive axons $(D O R-a)$. The terminal in C (DOR-t) contains DOR-LI that is seen along a portion of the axonal plasma membrane (small arrow). The peroxidase reaction product is also associated with adjacent cytoplasmic organelles, (Figure legend continues) 
sections of four animals). Specific cellular relationships between DORand Enk-immunoreactive profiles were expressed as a percentage of the total number of DOR- and Enk-immunoreactive elements that either were in contact or contained both antigens $(n=193)$.

Methodological considerations. The term $\delta$-opioid receptor-like immunoreactivity (DOR-LI) was used to describe the localization of the antipeptide antiserum used in this study to include the possibility that the antiserum may recognize structurally similar proteins. Based on several lines of evidence, however, we believe that the antiserum specifically recognizes DOR. DOR immunoreactivity was removed by adsorption with the corresponding p34 peptide in several brain regions known to contain high levels of DOR, as well as NG-108 cells, a cell line that expresses DOR. Moreover, dot blot analysis revealed that the DOR antiserum did not cross-react with peptide fragments from either the $\mu$ or $\kappa$-opioid receptors (Cheng et al., 1995). Furthermore, searches of GenBank have shown that the p34 peptide sequence has no significant sequence homology with other known peptides.

Avidin-biotin-peroxidase labeling is known to diffuse and therefore may lead to artifactual labeling (Beier, 1992). Diff usion may account for detection of immunoreactive cytoplasmic organelles that were adjacent to more intensely labeled plasma membranes. The peroxidase reaction product is, however, highly sensitive and therefore is able to detect discrete patterns of receptor immunoreactivity at the subcellular level. Our results are likely to underepresent the frequencies of associations between DOR and Enk because of the sparsity of immunogold labeling attributed in part to the small number of dense core vesicles, the presumed storage vesicle for Enk and other peptides (Zhu et al., 1986).

\section{RESULTS}

In the AcbSh, $60 \%$ of 626 DOR-labeled profiles were axon terminals and small unmyelinated axons, whereas the remainder $(35 \%)$ were mainly dendrites and dendritic spines. Within tissue dually labeled for DOR and Enk, $43 \%(n=193$ of 454) of the DOR-labeled profiles either contained Enk or contacted other profiles that contained the peptide.

\section{Localization of DOR immunoreactivity to axon terminals and their relationship to unlabeled and Enk- labeled terminals \\ DOR immunoreactivity is localized to large axon terminals}

Twenty-seven percent $(n=169$ of 626) of all DOR-labeled profiles were axon terminals that were between 0.5 and $1.5 \mu \mathrm{m}$ in diameter and contained loosely packed small synaptic vesicles (Figs. $1 A-C, 2 C$ ). Within these axon terminals, DOR-LI was associated with clusters of small synaptic vesicles (SSVs), coated vesicles, and/or smooth endoplasmic reticulum (Fig. 1A-C). These cytoplasmic organelles were often near plasma membranes that also showed DOR labeling. DOR-immunoreactive plasma membranes were apposed to unlabeled axons (Figs. 1C, 2A) and glial processes. Eighty-three percent (140 of 169) of the large DOR-labeled axon terminals formed symmetric synapses (Fig. $1 A, B)$. Seventeen percent ( 29 of 169 ) of DOR-labeled terminals formed asymmetric contacts (Fig. 1C). DOR-immunoreactive terminals that formed symmetric synapses contacted unlabeled dendrites, whereas unlabeled dendritic spines were contacted by terminals that formed asymmetric synapses (Fig. $1 A-C$ ).

\section{DOR labeling is localized to small axon terminals}

Twenty percent of all DOR-LI was associated with small axon terminals ( $n=122$ of 626 DOR-labeled profiles). These terminals were between 0.1 and $0.5 \mu \mathrm{m}$ in diameter and contained few small synaptic vesicles (Fig. 1B,D). The immunolabeling for DOR was associated with selective segments of the plasma membrane (Fig. $1 D)$ and also was seen along membranes of small synaptic vesicles (Fig. 1B). DOR-labeled small terminals formed symmetric punctate synapses with dendrites (Fig. $1 B, D$ ), some of which were immunoreactive for DOR (Fig. 1D). Other DOR-labeled small axon terminals lacked recognizable junctions and were apposed to unlabeled profiles.

\section{DOR immunolabeling is localized to small unmyelinated axons}

Thirteen percent of DOR-labeled profiles were small unmyelinated axons ( $n=85$ of 626 DOR-labeled profiles). These axons were $<0.1 \mu \mathrm{m}$ in diameter and rarely contained SSVs. In most small unmyelinated axons, DOR-LI was associated with the plasma membrane but also was observed within the cytoplasm (Figs. 1B,D, 2C, 3A, 4A). DOR-immunoreactive axons were either isolated (Fig. $1 B, D$ ) or were grouped in bundles with other DOR- or unlabeled axons (Figs. $2 C, 4 A$ ). These axons did not appear to form recognizable junctions with apposing profiles.

\section{DOR and Enk immunoreactivity are localized within apposing axon terminals}

The localization of DOR to axon terminals was also seen in tissue sections that were dually labeled for DOR and Enk. From the 193 contacts or colocalizations between DOR- and Enk-labeled profiles, $35 \%$ were appositions between differentially labeled axon terminals. Enk-labeled terminals were large $(>0.5 \mu \mathrm{m}$ in diameter) and contained loosely packed vesicles (Fig. 2A,B). Goldsilver particles indicating the presence of Enk were often seen in clusters near the perimeter of axons and sometimes contacted membranes of SSVs (Figs. 2, 3A, 4C).

DOR-labeled axons and axon terminals that were apposed to Enk-immunoreactive terminals varied in size $(0.1-1.5 \mu \mathrm{m}$ in diameter) (Fig. 2A), similar to those seen in singly labeled tissue sections. DOR immunoreactivity was not restricted to, and often was not present along, SSVs or discrete portions of immediately apposed axonal membranes (Fig. $2 A$ ).

\section{DOR and Enk immunoreactivity are colocalized in axon terminals}

In dually labeled tissue sections, $25 \%$ of all associations between DOR- and Enk-labeled profiles $(n=193)$ were axon terminals that contained both antigens. Dually labeled axon terminals were large $(>0.5 \mu \mathrm{m}$ in diameter), contained loosely packed small

\footnotetext{
Figure 3. Electron micrographs showing appositions between axon terminals labeled for either DOR or Enk $(A)$ and colocalization of DOR and Enk in axon terminals $(B, C)$. A, DOR-labeled terminal $(D O R-t)$ is apposed to a terminal that contains gold-silver particles for Enk $(E n k-t)$. The DOR peroxidase reaction product is associated with the plasma membrane (small arrows) and a nearby mitochondrion $(m)$. Gold-silver particles for Enk (arrowheads) are dispersed within the cytoplasm. B, Cross-section of a large axon terminal that contains peroxidase reaction product for DOR and gold-silver particles for Enk $(D L-t)$. The immunolabeling for DOR (small arrows) and Enk (arrowheads) is associated with small synaptic vesicles (SSV), but their immunoreactivities appear segregated within the axon terminal. $D L-t$ is apposed to an unlabeled dendrite $(U D)$. $C$, Longitudinally cut axon that contains immunoperoxidase labeling for DOR and immunogold labeling for Enk $(D L-t)$. The peroxidase reaction product is intensely localized to the plasma membrane of an intervaricose segment of the axon (small arrows), whereas gold-silver particles for Enk (arrowheads) are located within the varicosity. $D L$ - $t$ forms divergent symmetric synapses (curved arrows) with two unlabeled dendrites $(U D)$. In the same field, a DOR-immunoreactive small unmyelinated axon $(D O R-a)$ is seen within a group of unlabeled small axons $(U A)$. Scale bars, $0.25 \mu \mathrm{m}$.
} 

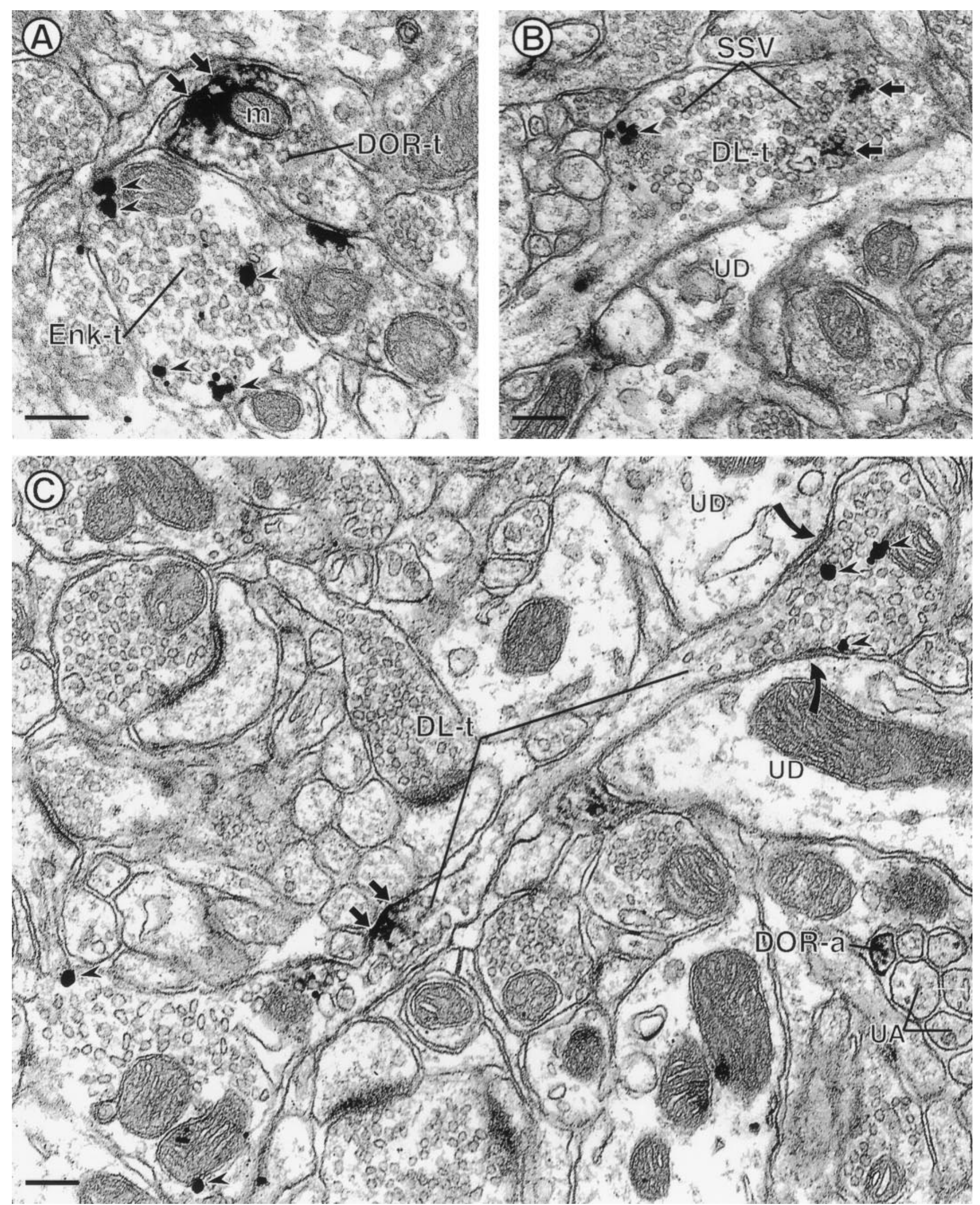
synaptic vesicles, and formed symmetric synapses with unlabeled dendrites (Fig. 2B,C). Gold-silver particles for Enk were contained within the cytoplasm, usually in association with SSVs. When present, dense core vesicles usually were Enkimmunoreactive. In these terminals, DOR-LI was associated with SSVs (Fig. 2B) and also was intensely localized to small segments of the plasma membrane in presynaptic portions of axons (Fig. $2 C)$. The DOR-immunoreactive plasma membranes were apposed to unlabeled small axons (Fig. 2C). In dually labeled axon terminals, the immunoreactivity for DOR and Enk was either segregated (Fig. 2B,C) or overlapped (data not shown).

\section{Localization of DOR immunoreactivity to dendrites and their relationship to Enk-labeled terminals \\ DOR labeling is localized to dendritic spines}

Twenty-six percent ( $n=164$ of 626) of DOR-labeled profiles were dendritic spines. Intense DOR immunolabeling was observed along portions of the dendritic plasma membrane, including postsynaptic densities of asymmetric-type junctions (Figs. 4, $5 C$ ) Synaptic DOR-LI was confined either to the postsynaptic density or was continuous with perisynaptic portions of the plasma membrane (Figs. 4, 5C) DOR immunoreactivity was also observed along selective extrasynaptic sites along the plasma membrane, which were apposed to unlabeled profiles, including glial processes, dendrites, and terminals (Fig. 4A). DOR-labeled nonsynaptic plasma membranes were also evident in spine necks, where membranes of the spiny apparatus also were densely immunoreactive (Fig. 4B). DOR-labeled spines received asymmetric synaptic input from unlabeled terminals (Figs. 4, 5C). These unlabeled terminals were up to $1.5 \mu \mathrm{m}$ in diameter and contained loosely packed, round vesicles. DOR-immunoreactive spines and spine necks were apposed to unlabeled axon terminals and dendrites (Figs. 4, 5C).

\section{DOR immunoreactivity is localized to dendritic shafts}

Nine percent of DOR-labeled elements were dendritic shafts ( $n=55$ of 626 DOR-labeled profiles). Within these dendrites, DOR immunoreactivity was localized to selective portions of the plasma membrane (Fig. 5A,B), including postsynaptic densities (Fig. $1 D)$. DOR-labeled dendrites were contacted by DORlabeled and unlabeled axon terminals (Figs. 2D, 5A,B). Unlabeled terminals formed asymmetric junctions (Fig. $2 D$ ) or lacked recognizable synapses (Fig. $5 A, B$ ). DOR-LI was also identified with saccules of smooth endoplasmic reticulum and occasionally with membranes of mitochondria, located near labeled portions of the plasma membrane (Fig. 5A,B).

\section{Enk-labeled terminals contact DOR-containing dendrites}

In dually labeled tissue sections, DOR immunoreactivity was present in dendrites that received synaptic contact from terminals both with and without Enk. These Enk-immunoreactive terminals contained gold-silver particles that were distal to the contacts with the DOR-labeled dendrites. DOR-immunoreactive spines received synaptic input only from unlabeled terminals; however, these spines sometimes were apposed to or near Enkimmunoreactive terminals (Fig. 4C). DOR-labeled spiny dendrites sometimes received symmetric junctions from multiple Enk-immunoreactive axon terminals (Fig. $5 C$ ). Even in these cases, DOR immunoreactivity was associated with spatially distinct regions that were mainly at asymmetric axospinous junctions (Fig. 5C).

\section{DOR and Enk immunoreactivity are colocalized in dendrites}

Eleven percent (22 of 193) of the immunolabeling for DOR and Enk was detected in the same dendrite. Peroxidase reaction product for DOR was localized to cytoplasmic membranes, including the spiny apparatus, and to postsynaptic densities of dendritic spines (Fig. 5C). Gold-silver particles for Enk were observed within the cytoplasm, in locations distal to the DOR immunoreactivity (Fig. 5C). Dually labeled dendrites received synaptic input from Enk-labeled and unlabeled axon terminals.

\section{Other DOR-labeled profiles and their relationship with Enk-immunoreactive profiles}

DOR immunolabeling is rarely localized to somata and glial processes

Three percent of the DOR-labeled profiles were cell bodies $(n=$ 17 of 626). Within the perikarya, DOR-LI was localized to cytoplasmic organelles, including the Golgi apparatus and smooth endoplasmic reticulum, and occasionally the plasma membrane. From all DOR and Enk contacts and colocalizations $(n=193)$, $2 \%$ were dually labeled perikarya. These somata had an abundance of cytoplasm and round, unindented nuclei. Two percent of DOR-labeled profiles were astrocytic processes $(n=14$ of 626 DOR-immunoreactive profiles), as defined by their irregular contour and/or intermediate filaments (Peters et al., 1991). Intense peroxidase labeling for DOR was seen along discrete portions of glial plasma membranes.

\section{DISCUSSION}

Our results provide the first ultrastructural evidence that in the AcbSh, DOR immunoreactivity is primarily localized to plasma membranes and vesicular structures within morphologically heterogenous types of axon terminals. Large DOR-immunoreactive axon terminals formed symmetric synapses and sometimes contained Enk or were apposed to Enk-immunoreactive terminals. These data suggest that activation of DOR by local endogenous opioids is involved in the presynaptic release of inhibitory amino acid neurotransmitters and possibly Enk. We also show that large terminals that formed asymmetric synapses or small terminals that formed symmetric synapses contain DOR, suggesting a potential role for DOR in the release of excitatory amino acids and possibly dopamine or acetylcholine. Finally, we show that DOR labeling is present along synaptic and extrasynaptic plasma membranes of dendritic spines, some of which received contact from Enk-labeled terminals. These latter data suggest that opioids may modulate the postsynaptic excitatory responses of spiny neurons in the AcbSh through activation of DOR.

\section{DOR immunoreactivity is localized primarily to axon terminals}

Most of the larger DOR-labeled terminals in the present study contained loosely packed small synaptic vesicles and formed symmetric-type junctions with dendrites. These are typical features of inhibitory-type terminals, which use GABA as their transmitter (Carlin et al., 1980). These results support physiological studies, which show that DOR ligands attenuate the presynaptic release of GABA in the striatum (Jiang and North, 1992), and other brain areas (Glaum et al., 1994; Tanaka and North, 1994). A smaller proportion of the large DOR-immunoreactive terminals contained densely packed small synaptic vesicles and formed asymmetric-type junctions with dendritic spines, indicative of excitatory-type terminals that use glutamate at their transmitter (Hendry et al., 1983). The localization of DOR to 

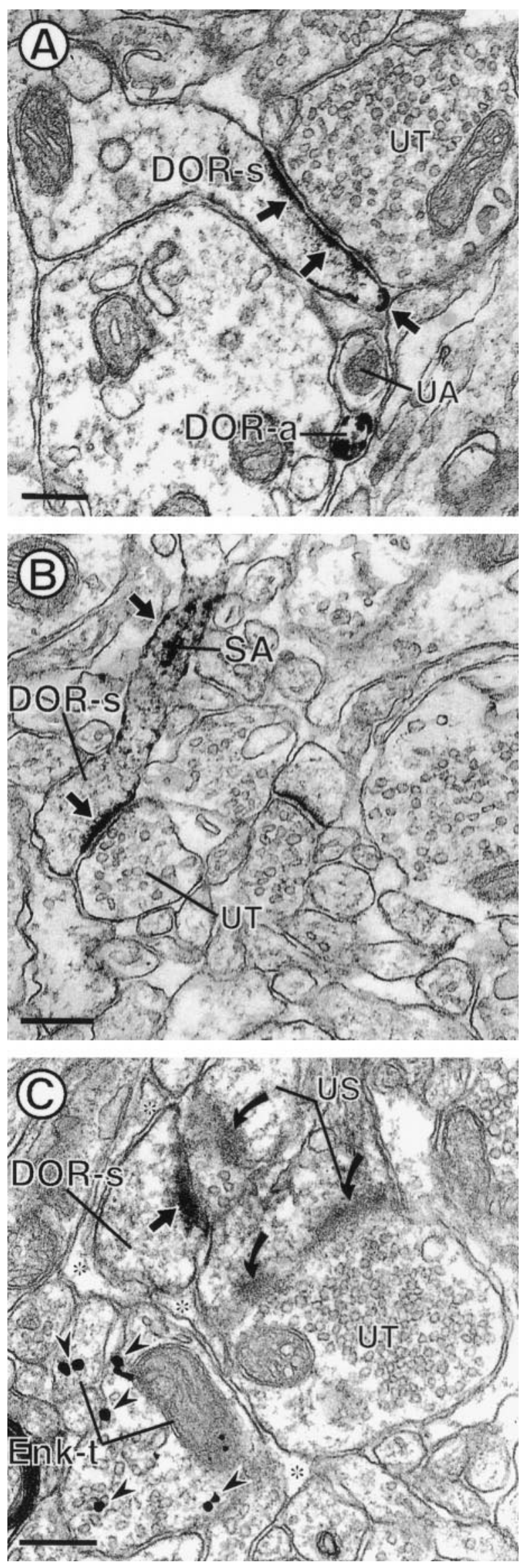

excitatory-type terminals supports electrophysiological studies that suggest the involvement of DOR ligands in the presynaptic release of glutamate (Jiang and North, 1992; Glaum et al., 1994; Tanaka and North, 1994). Within each type of terminal, DOR immunolabeling was infrequently localized to plasma membranes and more commonly was associated with clusters of small synaptic vesicles. In contrast, in presynaptic axons, DOR was preferentially localized to plasma membranes. The plasmalemmal localization of DOR provides a possible site for receptor-mediated attenuation of transmitter release through a reduction in calcium influx (Heijna et al., 1992; Stefani et al., 1994; Piros et al., 1996), because calcium channels show a similar subcellular distribution within axon terminals (Westenbroek et al., 1995). The vesicular localization of DOR suggests that activation of the receptor may inhibit calcium-dependent transmitter release directly, possibly through changes in stimulus-secretion-coupling processes, as seen in peripheral tissue (Sher et al., 1996). The localization of DOR to mainly inhibitory but also to excitatory-type terminals indicates that activation of the receptor in the AcbSh may modulate the release of GABA but also glutamate through two distinctive mechanisms, both of which may involve calcium regulation.

In the AcbSh, DOR labeling also was detected prominently within small axon terminals that either did not form recognizable junctions or showed poorly differentiated symmetric synapses. These axon terminals had the morphological characteristics and contacted targets similar to those that have been described for cholinergic and catecholaminergic terminals (Houser et al., 1983; Wainer et al., 1984; Phelps et al., 1985; Pickel et al., 1988; Pickel and Chan, 1990). In this regard, our data support the localization of DOR mRNA within acetylcholine-containing neurons of the striatum (LeMoine et al., 1994). Our data also are consistent with physiological studies that show DOR activation to inhibit presynaptic acetylcholine release in the Acb (Mulder et al., 1984; Lapchak et al., 1989; Heijna et al., 1990, 1992; Sandor et al., 1991). DOR ligands also are known to potentiate extracellular dopamine levels in the striatum; therefore, our data support the possibility of DOR localization within dopamine-containing terminals in this region (Chesselet et al., 1984; Spanagel et al., 1990; Pentney and Gratton, 1991; Suzuki et al., 1997). DOR ligandbinding and agonist-induced locomotor activity, however, are not altered after either intra-accumbens or intramesencephalic lesioning of dopaminergic input to the Acb (Kalivas et al., 1983; Unterwald et al., 1989; Dilts and Kalivas, 1990; Churchill and Kalivas, 1992), suggesting that dopamine terminals do not contain DOR. Ultra-

\footnotetext{
Figure 4. Electron micrographs showing DOR immunoreactivity in dendritic spines and their relationship with Enk-labeled terminals. The dendritic spines in $A$ and $B(D O R-s)$ show intense DOR-LI mainly localized to plasma membranes of postsynaptic densities and along nonsynaptic portions of dendritic spines (small arrows). $B$, DOR-LI within the spiny apparatus $(S A)$ and along the plasma membrane of a spine neck (small arrow). Both DOR-labeled spines receive asymmetric synaptic input from unlabeled terminals $(U T)$. C, Dendritic spine $(D O R-s)$ that has intense DOR labeling along the postsynaptic density (small arrow). DOR-s receives synaptic input from an unlabeled terminal that also contacts an unlabeled spine $(U S)$. DOR-s is also apposed to two axon terminals (Enk-t) that contain gold-silver particles for Enk (arrowheads). Enk-t are separated from DOR-s by glial processes (asterisks). The unlabeled terminal also forms a synapse with another spine (US), which lacks DOR immunoreactivity. In the same field, an unlabeled spine (US) forms a perforated asymmetric synapse (curved arrows) with an unlabeled terminal $(U T)$. Scale bars, $0.26 \mu \mathrm{m}$.
} 

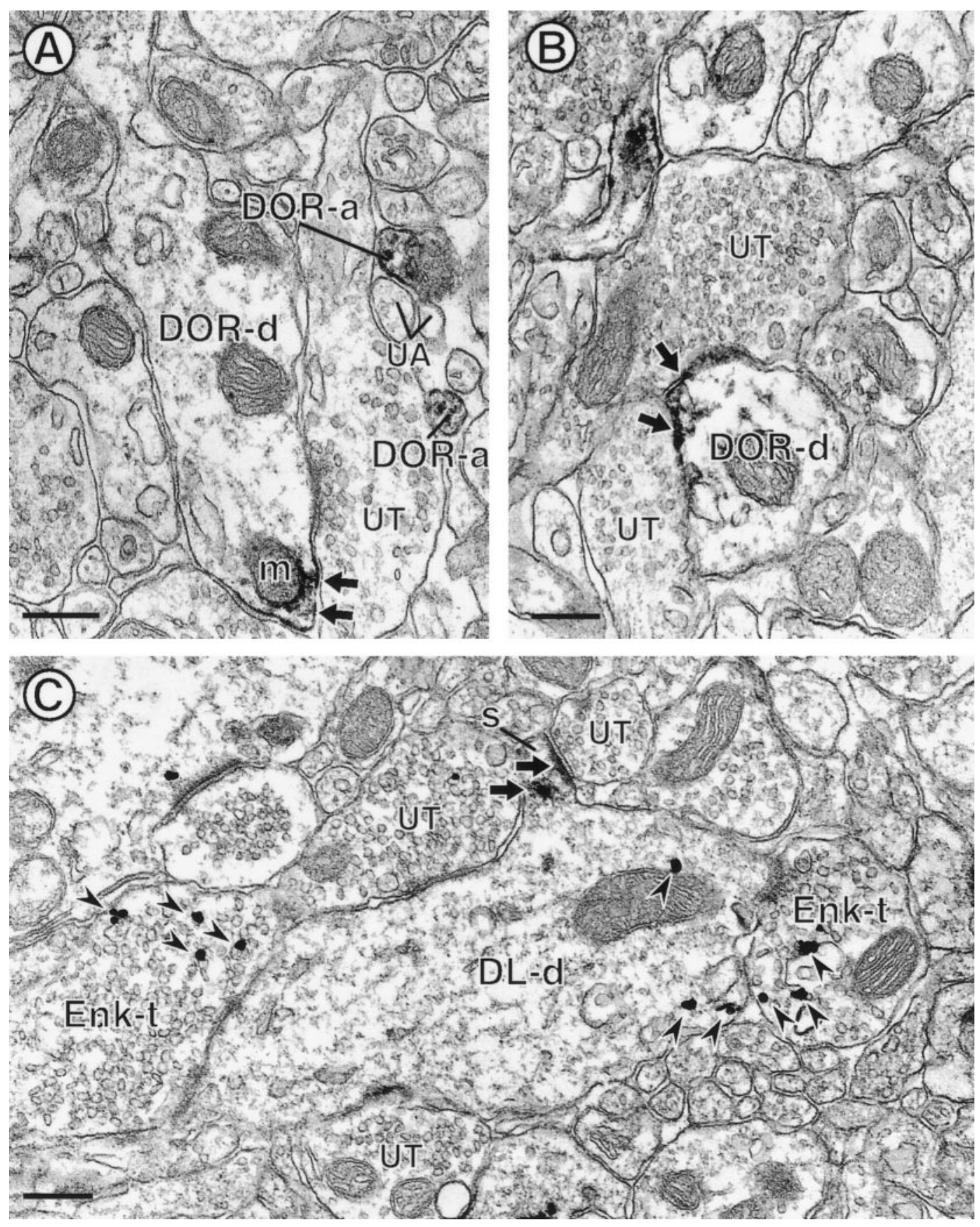

Figure 5. Electron micrographs showing DOR-LI in dendrites and their relationship to Enk. The dendrites in $A$ and $B$ (DOR- $d$ ) show peroxidase reaction product for DOR (small arrows) along selective portions of their plasma membranes. Diff use reaction product is also seen along the membranes of nearby cytoplasmic organelles, including a mitochondrion $(m)$ in $A$. Both of the DOR-labeled dendrites are apposed to unlabeled terminals $(U T)$. Within $A$, there are also two small unmyelinated axons that are labeled for DOR $(D O R-a)$ within a group of unlabeled axons $(U A)$. $C$, Dendrite that is dually labeled for DOR and Enk $(D L-d)$. The dendritic spine $(S)$ is intensely labeling for DOR (small arrows), whereas the gold-silver particles for Enk are contained within the shaft (arrowheads). $D L-d$ receives convergent input from two Enk-immunoreactive terminals (Enk-t) and two unlabeled terminals $(U T)$. Scale bars, $0.27 \mu \mathrm{m}$.

structural studies combining DOR antiserum with markers for acetylcholine and dopamine are necessary to address this issue definitively and are currently under investigation.

\section{DOR immunoreactivity is localized to axon terminals that either appose Enk-labeled terminals or contain Enk immunoreactivity}

In dually labeled tissue sections, DOR-labeled axon terminals were apposed to terminals that contained Enk. The DOR-labeled terminals varied in their morphological characteristics, as seen in singly labeled tissue. The apposing Enk-labeled terminals were large and formed symmetric synapses with unlabeled profiles. Synaptic contacts were not detected between DOR- and Enklabeled terminals, consistent with results seen previously in other brain areas (Cheng et al., 1995; Svingos et al., 1995). These results support physiological studies that indicate that Enk and Enk analogs modulate acetylcholine and dopamine release through 
activation of presynaptic DOR (Di Chiara and Imperato, 1988; Sandor et al., 1991). The present data also provide an anatomical basis for a local enkephalin source for activation of DOR.

DOR and Enk immunoreactivity were also detected within the same axon terminals. These dually labeled terminals were large and formed symmetric synapses with dendrites, consistent with the localization of DOR to Enk-containing neurons that use GABA as their primary transmitter (Aronin et al., 1984). These data suggest that DOR may act as a presynaptic heteroreceptor and/or autoreceptor that could modulate the release of Enk and GABA (Collin et al., 1994). These data are consistent with physiological studies that show that DOR agonists, including Enk, decrease inhibitory postsynaptic potentials in the striatum (Jiang and North, 1992; Yuan et al., 1992). Because GABA- and Enkcontaining neurons primarily project to regions outside of the Acb (Preston et al., 1979), our data suggest that DOR activation within the AcbSh could modulate Enk and/or GABAergic function in other regions (Maldonado-Irizarry et al., 1995).

\section{DOR immunoreactivity is localized to dendritic spines}

In the AcbSh, DOR immunoreactivity was localized to postsynaptic densities and extrasynaptic portions of plasma membranes within dendritic spines. This distribution is similar to that observed previously for DOR in various brain regions (Cheng et al., 1995; Svingos et al., 1995; Commons and Milner, 1996). These data provide evidence for synaptic and nonsynaptic sites by which DOR ligands could modulate the postsynaptic responsivity of excitatory transmission within spiny-type neurons. Plasmalemmal modulation of excitatory transmission may occur through changes in DOR-mediated potassium and/or calcium channel conductance (North et al., 1987; Stefani et al., 1994). In this regard, the cellular distribution of a G-protein-gated, inwardly rectifying potassium channel that couples to opioid receptors, also is highly localized within asymmetric postsynaptic densities and nonsynaptic portions of dendritic spines (Drake et al., 1997). Our data also concur with pharmacological studies in the striatum, which predict that opioids alter postsynaptic responses through modulation of calcium currents (Stefani et al., 1994). DOR-mediated alterations in calcium flux may underlie opiate modulation of NMDA receptor-mediated postsynaptic potentials, as seen in other brain regions (Chen and Huang, 1991). In this regard, it is interesting to note that NMDA receptors in the AcbSh have a distribution pattern similar to that of DOR (Gracy et al., 1997). Our results suggest that activation of DOR within spines may alter postsynaptic glutamatergic transmission through modulation of ion channel flux at synaptic and nonsynaptic sites.

\section{DOR labeling is localized to dendrites that are contacted by Enk-labeled terminals}

DOR-immunoreactive dendritic spines primarily received synaptic input from unlabeled terminals that formed asymmetric synapses but also were apposed to Enk-immunolabeled terminals. DOR-immunoreactive dendritic shafts also received direct synaptic input from Enk-labeled terminals. DOR immunoreactivity, however, was located at sites distal from Enk innervation. Both cases present evidence for nonsynaptic activation of DOR by local Enk sources, as documented previously in several brain regions for DOR, and the $\mu$-opioid receptor (Cheng et al., 1995; Svingos et al., 1995, 1996; Wang et al., 1996). These data suggest that opioid receptors could be activated by local peptide sources released through extracellular space (Jan and Jan, 1983; Pickel et al., 1995), providing further evidence that receptor activation may occur at a distance from peptide release (Thureson-Klein and Klein, 1990).

\section{Conclusions}

Our results show that presynaptic modulation of mainly inhibitory neurotransmission and possibly acetylcholine and/or dopamine release are the primary mechanisms for DOR-mediated locomotor activity and reinforcement in the AcbSh. To a lesser extent does our evidence suggest that DOR agonists modulate the presynaptic affects of glutamate transmission in this region. These results, in conjunction with the known circuitry in the AcbSh, indicate that the fundamental action of DOR ligands, including opiates, is presynaptic modulation of afferent inputs to spiny projection neurons. The presynaptic effects may be augmented or opposed by activation of postsynaptic DOR, which may produce changes in the responsivity of spiny neurons to excitatory afferents. These results support the hypothesis that spiny projection neurons in the Acb are opiate targets that are highly involved in DOR-mediated reward (Hubner and Koob, 1990).

\section{REFERENCES}

Alheid GF, Heimer L (1988) New perspectives in basal forebrain organization of special relevance for neuropsychiatric disorders: The striatopallidal, amygdaloid and corticopetal components of substantia innominata. Neuroscience 27:1-39.

Aronin N, DiFiglia M, Graveland GA, Schwartz WJ, Wu J-Y (1984) Localization of immunoreactive enkephalins in GABA synthesizing neurons of the rat neostriatum. Brain Res 300:376-380.

Beier K (1992) Light microscopic morphometric analysis of peroxisomes by automatic image analysis: advantages of immunostaining over the alkaline DAB method. J Histochem Cytochem 40:115-121.

Carlin RK, Grab DJ, Cohen RS, Siekovitz P (1980) Isolation and characterization of postsynaptic densities from various brain regions. Cell Biol 86:831-843.

Chan J, Aoki C, Pickel VM (1990) Optimization of differential immunogold-silver and peroxidase labeling with maintenance of ultrastructure in brain sections before plastic embedding. J Neurosci Methods 33:113-127.

Chen L, Huang L-YM (1991) Sustained potentiation of NMDA receptor-mediated glutamate responses through activation of protein kinase $C$ by a $\mu$ opioid. Neuron 7:319-326.

Cheng PY, Svingos AL, Wang H, Clarke CL, Jenab S, Beczkowska IW, Inturissi CE, Pickel VM (1995) Ultrastructural immunolabeling shows prominent presynaptic vesicular localization of $\delta$-opioid receptor within both enkephalin- and nonenkephalin-containing axon terminals in the superficial layers of the rat cervical spinal cord. J Neurosci 15:5976-5988.

Chesselet MF (1984) Presynaptic regulation of neurotransmitter release in the brain. Neuroscience 12:347-375.

Churchill L, Kalivas PW (1992) Dopamine depletion produces augmented behavioral responses to mu, but not a delta-opioid receptor agonist in the nucleus accumbens: lack of a role for receptor upregulation. Synapse 11:47-57.

Collin E, Mauborgne A, Bourgoin A, Benoliel JJ, Hamon M, Ceselin F (1994) Morphine reduces the release of met-enkephalin-like material from the rat spinal cord in vivo by acting at $\delta$ opioid receptors. Neuropeptides 27:75-83.

Commons KG, Milner TA (1996) Cellular and subcellular localization of $\delta$ opioid receptor immunoreactivity in the rat dentate gyrus. Brain Res 738:181-195.

Dauge V, Rossignol P, Roques BP (1988) Comparison of the behavioral effects induced by administration in rat nucleus accumbens or nucleus caudatus of selective $\mu$ and $\delta$ opioid peptides or kelatorphan an inhibitor of enkephalin-degrading-enzymes. Psychopharmacology 96:343-352.

Di Chiara G, Imperato A (1988) Drugs abused by humans preferentially increase synaptic dopamine concentrations in the mesolimbic system of freely moving rats. Proc Natl Acad Sci USA 85:5274-5278.

Dilts RP, Kalivas PW (1990) Autoradiographic localization of delta opioid receptors within the mesocorticolimbic dopamine system using radioiodinated [2-D-penicillamine, 5,D-penicillaline] enkephalin $\left({ }^{125} \mathrm{I}-\right.$ DPDPE). Synapse 6:121-132. 
Drake CT, Bausch SB, Milner TA, Chavkin C (1997) GIRK1 immunoreactivity is present in somata, dendrites and dendritic spines in the CA1 region of the hippocampus. Proc Natl Acad Sci USA 94:1007-1012.

Glaum SR, Miller RJ, Hammond DL (1994) Inhibitory actions of delta 1-, delta 2-, and mu-opioid receptor agonists in excitatory transmission in laminae II neurons of adult rat spinal cord. J Neurosci 14:4965-4971.

Goeders NE, Lane JD, Smith JE (1984) Self-administration of methionine enkephalin into the nucleus accumbens. Pharmacol Biochem Behav 20:451-455.

Gouarderes C, Tellez S, Tafani JAM, Zajac J-M (1993) Quantitative autoradiographic mapping of delta-opioid receptors in the rat central nervous system using $\left[{ }^{125} \mathrm{I}\right]\left[\mathrm{D}-\mathrm{Ala}^{2}\right]$ deltorphin-I. Synapse 13:231-240.

Gracy KN, Svingos AL, Pickel VM (1997) Dual ultrastructural localization of $\mu$-opioid receptors and NMDA-type glutamate receptors in the shell of the rat nucleus accumbens. J Neurosci 17:4839-4848.

Heijna MH, Padt M, Hogenboom F, Porthoghese PS, Mulder AH, Schoffelmeer ANM (1990) Opioid receptor-mediated inhibition of dopamine and acetylcholine release from rat brain slices: differences between nucleus accumbens, olfactory tubercle and frontal cortex in receptor types involved. Eur J Pharmacol 181:267-278.

Heijna MH, Hogenboom F, Mulder AH, Schoffelmeer ANM (1992) Opioid receptor-mediated inhibition of ${ }^{3} \mathrm{H}$-dopamine and $14 \mathrm{C}$ acetylcholine release from rat nucleus accumbens slices. A study on the possible involvement of $\mathrm{K}+$ channels and adenylate cyclase. Naunyn Schmeiderbergs Arch Pharmacol 345:627-632.

Hendry SHC, Houser CR, Jones EG, Vaughn JE (1983) Synaptic organization of immunocytochemically identified GABA neurons in the monkey sensory-motor cortex. J Neurocytol 12:639-660.

Houser CR, Crawford GD, Barber RP, Salvaterra PM, Vaughn JE (1983) Organization and morphological characteristics of cholinergic neurons: and immunocytochemical study with a monoclonal antibody to choline acetyltransferase. Brain Res 266:97-119.

Hsu S-M, Raine L, Fanger H (1981) Use of avidin-biotin-peroxidase complex (ABC) immunoperoxidase techniques: a comparison between $\mathrm{ABC}$ and unlabeled antibody (PAP) procedures. J Histochem Cytochem 29:577-580.

Hubner CB, Koob GF (1990) The ventral pallidum plays a role in mediating cocaine and heroin self-administration in the rat. Brain Res 508:20-29.

Jan YN, Jan LY (1983) A LHRH-like peptidergic neurotransmitter capable of "action at a distance" in autonomic ganglia. Trends Neurosci 6:320-325.

Jiang ZG, North RA (1992) Pre- and postsynaptic inhibition by opioids in rat striatum. J Neurosci 12:356-361.

Kalivas PW, Widerlow E, Stanley D, Breese G, Prange AJ (1983) Enkephalin action on the mesolimbic system: a dopamine-dependent and a dopamine-independent increase in locomotor activity. J Pharmacol Exp Ther 227:229-237.

Lapchak PA, Araujo DM, Collier B (1989) Regulation of endogenous acetylcholine release from mammalian brain slices by opiate receptors: hippocampus, striatum and cerebral cortex of guinea-pig and rat. Neuroscience 31:313-325.

LeMoine C, Kieffer B, Gaveriaux-Ruff C, Befort K, Bloch B (1994) Delta-opioid receptor gene expression in the mouse forebrain: localization in cholinergic neurons of the striatum. Neuroscience 62:635-640.

Leranth C, Pickel VM (1989) Electron microscopic pre-embedding double immunostaining methods. In: Tract tracing methods 2, recent progress (Heimer L, Zaborsky L, eds), pp 129-172. New York: Plenum.

Longoni R, Spina L, Mulas A, Carboni E, Garau L, Melchiorri P, Di Chiara G (1991) (D-Ala2)deltorphin II: D1-dependent stereotypies and stimulation of dopamine release in the nucleus accumbens. J Neurosci 11:1565-1576.

Maldonado-Irizarry CS, Swanson CJ, Kelley AE (1995) Glutamate receptors in the nucleus accumbens shell control feeding behavior via the lateral hypothalamus. J Neurosci 15:6779-6788.

Mansour A, Khachaturian H, Lewis ME, Akil H, Watson SJ (1987) Autoradiographic differentiation of mu, delta and kappa opioid receptors in the rat forebrain and midbrain. J Neurosci 7:2445-2464.

Mansour A, Fox CA, Akil H, Watson SJ (1995) Opioid-receptor mRNA expression in the rat CNS: anatomical and functional implications. Trends Neurosci 18:22-29.

Meyer ME, McLaurin BI, Meyer ME (1995) Intra-accumbens 81 -opioid agonist, pCl-DPDPE, differentially affects patterns of locomotor activity. Pharmacol Biochem Behav 51:359-362.

Mogenson GJ, Swanson LW, Wu M (1980) From motivation to action: Functional interface between the limbic system and the motor system. Prog Neurobiol 14:69-97.

Mulder AH, Schoffelmeer ANM (1993) Multiple opioid receptors and presynaptic modulation of neurotransmitter release in the brain. In: Handbook of experimental pharmacology, opioids I, Vol 4 (Herz A, ed), pp 125-144. Berlin: Springer.

Mulder AH, Wardeh G, Hogenboom F, Frankhuyzen AL (1984) Kappa and delta-opioid receptor agonists differentially inhibit striatal dopamine and acetylcholine release. Nature 308:278-280.

Negus SS, Henriksen SJ, Mattox A, Pasternak GW, Porthoghese PS, Takemori AE, Weigner MB, Koob GF (1993) Effects of antagonists selective for $m u$, delta and kappa opioid receptors in the reinforcing effects of heroin in rats. J Pharmacol Exp Ther 265:1245-1252.

North RA, Williams JT, Suprenant A, Christie MJ (1987) $\mu$ and $\delta$ opioid receptors both belong to a family of receptors that are couples to potassium channels. Proc Natl Acad Sci USA 84:5487-5491.

Paxinos G, Watson C (1986) The rat brain in stereotaxic coordinates. New York: Academic.

Pentney RJW, Gratton A (1991) Effects of local delta and mu opioid receptor activation on basal and stimulated dopamine release in striatum and nucleus accumbens of rat: and in vivo electrochemical study. Neuroscience 45:95-102.

Peters A, Palay SL, Webster HdeF (1991) The fine structure of the nervous system, neurons and their supporting cells, Ed 3. New York: Oxford UP.

Phelps PE, Houser CR, Vaughn JE (1985) Immunocytochemical localization of choline acetyltransferase within the rat neostriatum: a correlated light and electron microscopic study of cholinergic neurons and synapses. J Comp Neurol 238:286-307.

Pickel VM, Chan J (1990) Spiny neurons lacking choline acetyltransferase immunoreactivity are major targets of cholinergic and catecholaminergic terminals in rat striatum. J Neurosci Res 25:263-280.

Pickel VM, Towle AC, Joh TH, Chan J (1988) Gamma-aminobutyric acid in the medial rat nucleus accumbens: ultrastructural localization in neurons receiving monosynaptic input from catecholaminergic afferents. J Comp Neurol 272:1-14.

Pickel VM, Chan J, Veznedaroglu E, Milner TA (1995) Neuropeptide Y and dynorphin-immunoreactive large dense-core vesicles are strategically localized for presynaptic modulation in the hippocampal formation and substantia nigra. Synapse 19:160-169.

Piros ET, Prather PL, Law PY, Evans CJ, Hales TG (1996) Voltagedependent inhibition of $\mathrm{Ca}^{2+}$ channels in $\mathrm{GH} 3$ cells by cloned mu- and delta-opioid receptors. Mol Pharmacol 50:947-956.

Preston RJ, Bishop GA, Kitai ST (1979) Medium spiny neuron projection form the rat striatum: an intracellular horseradish peroxidase study. Brain Res 183:253-263.

Reynolds ES (1963) The use of lead citrate at high $\mathrm{pH}$ as an electronopaque stain in electron microscopy. J Cell Biol 17:208.

Sandor NT, Lendvai B, Vizi ES (1992) Effect of selective opiate antagonists on striatal acetylcholine and dopamine release. Brain Res Bull 29:369-373.

Sher E, Cesare P, Codignola A, Clementi F, Tarroni P, Pollo A, Magnelli V, Carbone E (1996) Activation of delta-opioid receptors inhibits neuronal-like calcium channels and distal steps of $\mathrm{Ca}\left({ }^{2+}\right)$-dependent secretion in human small-cell lung carcinoma cells. J Neurosci 16:3672-3682.

Shippenberg TS, Herz A (1988) Motivational effects of opioids: influence of D-1 versus D-2 receptor antagonists. Eur J Pharmacol 151:233-242.

Shippenberg TS, Bals-Kubic R, Herz A (1987) Motivational properties of opioids: evidence that an activation of $\delta$-opioid mediates reinforcement properties. Brain Res 436:234-239.

Spanagel R, Herz A, Shippenberg TS (1990) The effects of opioid peptides on dopamine release in the nucleus accumbens: an in vivo microdialysis study. J Neurochem 55:1734-1740.

Stefani A, Surmeier DJ, Bernardi G (1994) Opioids decrease highvoltage activated calcium currents in acutely dissociated neostriatal neurons. Brain Res 642:339-343.

Suzuki T, Yoshiike M, Mizoguchi H, Kamei J, Misawa M, Nagase H (1994) Blockade of delta-opioid receptors prevents morphine-induced place preference in mice. Jpn J Pharmacol 66:131-137.

Suzuki T, Tsuji M, Mori T, Ikeda H, Misawa M, Nagase H (1997) 
Involvement of dopamine-dependent and -independent mechanisms in the rewarding effects mediated by delta opioid receptor subtypes in mice. Brain Res 744:327-334.

Svingos AL, Cheng PY, Clarke CL, Pickel VM (1995) Ultrastructural localization of $\delta$-opioid receptor and $\mathrm{Met}^{5}$-enkephalin immunoreactivity in rat insular cortex. Brain Res 700:25-39.

Svingos AL, Moriwaki A, Wang JB, Uhl GR, Pickel VM (1996) Ultrastructural immunocytochemical localization of $\mu$-opioid receptors in rat nucleus accumbens: extrasynaptic plasmalemmal distribution and association with Leu ${ }^{5}$-enkephalin. J Neurosci 16:4162-4173.

Swanson LW (1992) Brain maps: structure of the rat brain. Amsterdam: Elsevier.

Tanaka E, North RA (1994) Opioid actions on rat anterior cingulate cortex neurons in vitro. J Neurosci 14:1106-1113.

Thureson-Klein AK, Klein RL (1990) Exocytosis from neuronal large dense-cored vesicles. Int Rev Cytol 121:67-126.

Unterwald EM, Tempel A, Koob GF, Zukin RS (1989) Characterization of opioid receptors in rat nucleus accumbens following mesolimbic dopaminergic lesions. Brain Res 505:111-118.

Wainer BH, Bolam JP, Freund TF, Henderson Z, Totterdell S, Smith AD (1984) Cholinergic synapses in the rat brain: a correlated light and electron microscopic immunohistochemical study employing a monoclonal antibody against choline acetyltransferase. Brain Res 308:69-76.

Wang H, Moriwaki A, Wang JB, Uhl GR, Pickel VM (1996) Ultrastructural immunocytochemical localization of $\mu$ opioid receptors and $\mathrm{Leu}^{5}$ enkephalin in the patch compartment of the rat caudate-putamen nucleus. J Comp Neurol 375:659-674.

West TEG, Wise RA (1988) Effects of naltrexone on nucleus accumbens, lateral hypothalamic and ventral tegmental self-stimulation ratefrequency functions. Brain Res 462:126-133.

Westenbroek RE, Sakurai T, Elliot EM, Hell JW, Starr TV, Snutch TP, Catterall WA (1995) Immunocytochemical identification and subcellular distribution of the alpha 1A subunits of brain calcium channels. J Neurosci 15:6403-6418.

Yuan X, Madamba S, Siggins GR (1992) Opioid peptides reduce synaptic transmission in the nucleus accumbens. Neurosci Lett 134:223-228.

Zhu PC, Thureson-Klein AK, Klein RL (1986) Exocytosis from large dense cored vesicles outside the active synaptic zones of terminals within the trigeminal subnucleus caudalis: a possible mechanism for neuropeptide release. Neuroscience 19:33-54.

Zito KA, Vickers G, Roberts DC (1985) Disruption of cocaine and heroin self-administration following kainic acid lesions of the nucleus accumbens. Pharmacol Biochem Behav 23:1029-1036. 